\title{
On the Reform of Tourism Management Specialty
}

\author{
Yongle Chen
}

\author{
Jiangxi Vocational Technical College of lndustry \& Trade, Jiangxi, Nanchang, 330038 \\ 739960103@qq.com
}

\begin{abstract}
Under the background of new era, with the continuous development of social economy, people's living standard has been greatly promoted, people are no longer merely content with the basic requirements of life, at the same time also more and more care about the higher level of spiritual pursuit and pleasures of the body and mind, so the development of domestic tourism is very rapidly, and tourism management is with the development of tourism and development. For tourism enterprises to provide more professional tourism management talents, colleges and universities must change the professional tourism management teaching methods and teaching system, as much as possible, improve students' professional ability and professional quality, to provide professional high-quality talents for tourism industry, to provide fresh blood to the development of tourism, so as to promote the development of tourism, so this article is mainly about tourism management specialty in the teaching reform was discussed in this paper.
\end{abstract}

Keywords : Tourism management, Teaching reform, Reform, Management professional

\section{浅谈旅游管理专业教学改革思路}

\author{
陈永乐
}

\author{
江西工业贸易职业技术学院 江西 南昌 330038 \\ 739960103@qq.com
}

\section{摘要}

在新时代背景下, 随着社会经济的不断发展, 人们的生活水平也得到了极大地提升, 人们已经不再仅仅满足 于基本的生活需求, 同时也越来越在乎更高层次的精神追求和身心上的享受, 因此当下国内旅游业的发展十 分迅猛, 而旅游管理专业也随着旅游业的发展而发展。为了给旅游企业提供更多的旅游管理专业人才, 高校 必须改变旅游管理专业教学方法和教学体系, 尽可能的提升学生的专业能力和职业素养, 从而为旅游业提供 专业的高素质人才, 为旅游业的发展提供新鲜血液, 从而促进旅游业的发展, 因此本文也主要围绕旅游管理 专业在教学改革上进行了一定的探讨。

\section{旅游管理; 教学改革; 改革; 管理专业}

\section{1. 旅游管理专业教学改革的必然性}

\section{1. 旅游管理专业的专业特征所决定}

旅游管理专业的专业特征就是偏向实际操作的, 旅游管理专业的专业特性就决定了在旅游管理专业 的教学中需要进行及时的实践操作, 只有将该专业的 实践理念融入到对学生的培养中去才会真正对学生 的专业能力的提升有所帮助, 从而能够对学生的专业 起到支持作用, 在旅游行业对专业人才的需求方面主
要是偏向于专科层次的人才, 在本科教育方面仍然处 于不足的阶段。因此旅游管理专业想要寻求新的发展 就必须要在专业教学上进行改革。

\section{2. 旅游业的行业发展要求}

在国民经济水平得到显著的提升之后，人们对于 生活的需求已经慢慢从对生活基本需求过渡为享受 型需求，旅游行业发展十分繁荣，无论是在旅游项目 和地域旅游文化的挖掘上都取得了一定的成果, 这些 
现象同样也表明我国旅游行业发展十分迅速，因此不 论是为规范旅游行业的管理, 还是为了促进旅游行业 的发展, 都需要适应旅游行业的发展需求, 对旅游管 理专业教学进行改革。

\section{3. 当下旅游资源的有限性需求}

在当今旅游行业飞速发展的今天, 旅游业中对地 域文化的挖掘和对当地自然资源的利用和开发, 旅游 行业中对旅游景点的过度开发问题已经逐渐暴露出 来，很大原因是没有对旅游资源进行合理的开发和管 理应用。包括政府部门也没有及时地对旅游开发管理 过程进行重视, 地方部门对当地的旅游资源开发管理 也没有规范管理, 这就会导致开发过度, 因此, 当下 旅游资源的利用开发问题已经成了当下需要迫切关 注的一个问题，因此，面对当下旅游资源的过度开发 问题和对旅游资源保护的需求, 高校就不需要要结合 当下时代发展的趋势对旅游管理专业人才进行进一 步的培养, 无论是在旅游管理专业知识上还是在对环 保意识的培养上都是需要高校方面重视起来, 在旅游 管理专业的教学方面不能再延续传统的教学模式, 同 样高校方面要想在教学方面取得一定的成果就要及 时对旅游管理专业的教学进行改革, 顺应时代的发展。

\section{2. 高校旅游管理专业教学的现状及存在的 问题}

随着旅游业的迅猛发展, 旅游管理专业成为了一 个就业前景非常良好的专业, 因此也有越来越多的学 生会报考旅游管理专业, 想要从事旅游管理方面的职 业, 而由于近几年高校也在不断扩招, 所以旅游管理 专业的规模也越来越大, 但是当学生的人数得到大幅 度的增长, 教学管理变得更加艰难。尤其是在我国高 校旅游管理专业教学中还存在着非常多的问题, 这些 问题不仅体现在旅游管理专业教育教学方面, 也体现 在旅游管理专业师资力量建设方面。而这些问题阻碍 了高校旅游管理专业教学的发展, 也影响了旅游管理 专业人才培养的效果。

\section{1. 师资力量和配比存在不足}

高校的教育教学质量和教育教学效率也就体现 了高校的师资力量。师资力量作为教育教学中最为关 键的一个因素, 学校必须要重视师资队伍的建设, 而 教师也必须要不断更新自己的知识体系, 提升自己的 专业能力和教育教学能力, 尽可能的激发学生的学习 兴趣, 引导学生主动探索旅游管理专业知识。但是目 前的情况是高校中专业的旅游管理专业教师较少, 而 且大部分教师都非常缺乏实践经验, 因此在实践方面 能够给予学生的帮助非常有限。

\section{2. 教学理念不够科学}

随着时代的变化, 高效旅游管理专业的教学理念 也必须要得到变化, 但是目前大部分高校的旅游管理
专业的教学理念还十分传统, 只重视理论教学, 但是 却忽略了实践教学，而高校旅游管理专业培养的是实 操型人才, 如果不重视实践教学, 学生的实践能力难 以得到大幅度的提升, 在对学生的理论教学中, 教师 过于关注学生对知识的掌握, 但是却不够重视对学生 职业素养的培养。无论是专业知识, 专业能力还是职 业素养, 都是学生的就业竞争力, 是学生参与就业时 所必须要展现出来的职业能力。但是如果在轻视实践 教学, 轻视素质培养的情况下, 学生的职业能力是有 欠缺的, 也不足以满足社会和企业对学生的要求。

\section{3. 教学方式不够先进}

教材是教学的基本, 教学是围绕教材而展开的, 而教学的内容主要也是教材的内容, 如果教材出现问 题, 那么教学的质量也难以得到保障。但是教师不应 该将教材当做教学的唯一根据, 而是应该根据教学所 框定的内容进行适当的拓展, 帮助学生开拓视野。而 当前高校旅游管理专业所使用的教材内容相对滞后, 并且不注重创新, 大大影响了旅游管理专业的教学效 率。除此之外，教师的教学手段也并没有随着信息技 术的兴起而变化, 依然采用的是传统的教学手段进行 教学, 而传统的教学手段虽然有其益处, 但是也很容 易使学生感到疲㤂和抗拒。

\section{4. 专业理论知识和实践知识脱节}

旅游管理专业本身就是一门实践大于理论的一 个专业领域, 在当下高校的旅游管理教学的过程中很 容易会出现的就是教学目标中理论大于实践的情况 出现, 这样对于旅游管理专业的人才培养十分不利。 针对旅游管理专业中的教学现状, 各高校都纷纷作了 一定的努力, 积极开发了一些实践类的课程, 和企业 进行校企合作实习实践, 但并没有取得很好的教学成 果, 学生的实践能力还是没有得到切切实实的提升, 实践教学的教学目标也没有十分明确, 这就导致实践 教学并没有起到预期的效果。还有一个很大的原因是 旅游管理专业的高校学生对于旅游业的接触还是不 够, 难以触及到旅游行业中最核心的机会, 这就会导 致学生在学校学习很多的理论知识, 但在是工作岗位 中并不能很好地应用, 专业知识和实践知识无法产生 联结, 和实际岗位脱节。

\section{5. 课堂教学和企业实际人才需求不匹配}

在旅游行业中很重要的就是服务水平, 并且旅游 行业的行业性质也就是服务, 在旅游行业的市场上由 于人们的需求的改变, 对于旅游管理的专业人才的需 求也随之改变, 但在高校的旅游管理教学课堂中并不 能及时捕捉到这些市场的改变, 存在很大的信息滞后 性, 学生们所学习的内容也不是市场最新的需求。在 高校旅游管理专业中要时刻以市场需求为导向进行 课堂教学, 把握市场的发展趋势, 培养能够适应旅游 行业发展的实践性人才。高校旅游管理专业的课堂教 
学与企业的实际人才需求的不匹配就导致了学生无 法找到期望的工作，企业方面也无法招聘到适应岗位 需求的高素质人才。

\section{6. 学生校外实习质量参差不齐}

旅游管理专业学生进行校外实习实践是一个很 好的接触行业的机会, 但很多情况下旅游管理企业并 不愿意招聘短期的实习生, 这样就可以大大降低企业 的招聘成本, 但学生通常都没有很长的实习时间, 企 业通常都会要求半年以上才能够转正, 而学生方面并 不能满足企业在时间上的要求, 并且学生对企业的岗 位也并不能十分确定, 需要进行一段时间的轮岗期才 能够确定自身的兴趣和优势, 但在高校通常都是在大 学的最后一个学期的长实习期, 学生在这个阶段的压 力很大, 不仅仅要在实习岗位中努力学习工作, 同时 还要做学校布置的毕业事项, 这样学生在校外的实习 质量根本就无法得到很好的保证, 学生等到真正进入 实习岗位中, 就无法很好地适应企业岗位的需求, 学 生在工作岗位中也无法快速适应, 这样学生在走上工 作岗位后就会引发很多问题。

\section{3. 改革旅游管理专业教学的措施及思路}

\section{1. 加强师资队伍建设}

建设旅游管理专业师资队伍的重点在于提升教 师的实践经验, 因为大部分教师都是具备一定的理论 知识能力的, 只是因为缺乏实践经验, 而无法给学生 带来更好的实践指导, 因此高校应该组织这一部分教 师进行培训, 提升这部分教师的实践经验和实践能力, 当然高校也可以和企业取得合作, 让教师作为科研人 才到企业汲取更多的经验, 一方面教师能够利用自己 的专业能力给企业带来更多科研方面的帮助, 另一方 面企业也可以给予教师更多实践的机会, 而同时高校 也要招收更多的双师型教师。

\section{2. 创新教学方式, 丰富教学内容}

紧紧围绕教材来进行教学是不足以满足学生的 学习需求的, 教师应该更多方面, 多角度的丰富教学 内容, 让学生感受到旅游管理专业知识的魅力, 引导 学生主动学习旅游管理专业知识, 同时教师也应该创 新自己的教学方式, 又适时采用多种教学方式进行教 学, 这样能够吸引学生的注意力, 使课堂教学更加具 有趣味性。当然, 教师也可以通过多媒体进行教学, 在多媒体上利用图片和视频等教学资源, 让学生更加 直观清晰地了解到教学内容, 而如果学校的资金充裕, 教师可以带领学生亲自走访旅游景点, 模拟旅游管理 的流程, 让学生更加能够深入其中。
表 1改革旅游管理专业教学的措施及思路

\begin{tabular}{|c|c|c|}
\hline \multicolumn{3}{|c|}{ 改革旅游管理专业教学的措施及思路 } \\
\hline $\begin{array}{c}\text { 加强师资队伍建 } \\
\text { 设 }\end{array}$ & $\begin{array}{c}\text { 创新教学方 } \\
\text { 式, 丰富教学 } \\
\text { 内容 }\end{array}$ & $\begin{array}{c}\text { 努力建立科学 } \\
\text { 的课程体系 }\end{array}$ \\
\hline $\begin{array}{l}\text { 加快高校师资的 } \\
\text { 培养, 既要注重 } \\
\text { 教师的教学能 } \\
\text { 力, 又要保证教 } \\
\text { 师具有本专业实 } \\
\text { 际的工作经验, } \\
\text { 培养双师型教 } \\
\text { 师, 可以采取教 } \\
\text { 师进修或者到企 } \\
\text { 业挂职的方式, } \\
\text { 学习先进教学经 } \\
\text { 验和教学方法, } \\
\text { 是高教师的实践 } \\
\text { 经验, 进而提高 } \\
\text { 教学质量。 }\end{array}$ & $\begin{array}{l}\text { 带领学生到当 } \\
\text { 地的酒店、饭 } \\
\text { 店、旅行社、 } \\
\text { 宾馆等去实习 } \\
\text { 或上岗, 以更 } \\
\text { 好地观察并了 } \\
\text { 解企业的运营 } \\
\text { 管理。带领学 } \\
\text { 生到旅游景 } \\
\text { 点, 以更好地 } \\
\text { 模拟导游的带 } \\
\text { 队过程等。总 } \\
\text { 的来讲, 就是 } \\
\text { 要尽可能地丰 } \\
\text { 富教学的内 } \\
\text { 容, 提高教学 } \\
\text { 的趣味性。 }\end{array}$ & $\begin{array}{l}\text { 高校在为旅游 } \\
\text { 管理专业学生 } \\
\text { 设立课程的时 } \\
\text { 候, 要做到少 } \\
\text { 而精, 在设置 } \\
\text { 专业必修课的 } \\
\text { 同时, 设立一 } \\
\text { 些选修课, 让 } \\
\text { 学生在学习中 } \\
\text { 有所选择, 按 } \\
\text { 照自己的喜好 } \\
\text { 和长处, 吸收 } \\
\text { 一些其他领域 } \\
\text { 的知识, 提高 } \\
\text { 学生的综合素 } \\
\text { 质。 }\end{array}$ \\
\hline
\end{tabular}

\section{3. 努力建立科学的课程体系}

高校在设置旅游管理专业课程时, 就要考虑到学 生学习的需求, 并且尽可能地少设置课程, 但是丰富 课程内容, 这样就能够充实学生的学习生活, 但不会 使学生感受到更大的压力, 并且学校还可以开设一部 分选修课, 让学生根据自己的兴趣爱好以及自己未来 的职业倾向选择合适的选修课, 这样也能够引导学生 更加深入的探索旅游管理专业知识, 而因为旅游管理 专业本身就是一门知识较为混杂的课程。所以学生也 可以通过选修课了解更多方面的知识, 来丰富自己的 专业。

\section{4. 结论}

总而言之, 为了学生未来的发展, 以及学生学习 的需求, 高校必须改革旅游管理专业教学体系和教学 方法, 因为在目前的旅游管理专业教学体系中还有很 多问题存在, 而这些问题影响了学生能力的提升, 所 以高校也必须要探索出一条适合高校发展和实施的 改革创新路径, 需要注意的是, 不同高校的旅游管理 专业存在细微区别, 所以高校应该按照自身的教学情 况来制定改革计划, 并在改革过程中观察学生的学习 情况以及社会反应, 根据学生学习的结果以及社会的 反馈来调整改革计划, 使改革计划能够更加贴合高校 旅游管理专业教学改革的需求。 


\section{REFERENCES}

[1] Liang Qin. Teaching Innovation Path of Tourism Management Major in Higher Vocational Colleges under the Background of Construction of First-class Specialty Groups [J]. Contemporary Tourism,2020,18(36):87-88

[2] Zhang Cheng. Research on the "Four in One" Inschool Practical Teaching System of Tourism Management Major in Local Application-oriented Universities -- Taking Liupanshui Normal University as an Example [J]. Green Technology,2020(23):245-248.

[3] Liao Zhongdi. Research on the Ideological and Political Reform of Tourism Management Specialty Courses -- Taking "Tourism Marketing" as an Example [J]. Heilongjiang Education (Higher Education Research and Evaluation),2020(12):2931.

[4] Li Yongan, Liu Qiong, Shi Yujie. Research on the Case Teaching Mode of Tourism Management Major in Jiangxi Universities under the Strategy of Strong Province of Tourism [J]. Rural Economy and Science and Technology,2020,31(21):330-331.

[5] Luo Chunyu, Li Xia, Xu Hong. Teaching Practice Research on the Integration of Courses and Certificates for Tourism Management in Higher Vocational Colleges under the "1+X" Certificate System [J]. Science and Technology Innovation and Productivity,2020(11):81-84.

[6] Bai Qian. Innovation Path of Undergraduate Practice Teaching Reform of Tourism Management Major in the New Era [J]. Contemporary Tourism,2020,18(30):62-63.

[7] Hu Xiaoxia. Construction of Practical Teaching System for Tourism Management Major Based on Innovation Ability Cultivation [J]. Rural Family Staff,2020(23):267.

[8] Chen Jianping. Construction of Practical Teaching System for Undergraduate Tourism Management Major from the Perspective of the Integration of Industry and Education [J/OL]. Journal of Inner Mongolia agricultural university (social science edition) : 1-9 [2021-01-11]. HTTP: / / http://kns.cnki.net/kcms/detail/15.1207.g.20201014 .1406.005.html.

[9] Wu Yali. Research on the Influence Mechanism of the Integration Effect of Practical Teaching Process in Colleges and Universities -- A Case Study of Tourism Management Major [J]. Heilongjiang Science,2020,11(19):48-49.
[10] Wang Juan, Wen Fei, Zhu Guoxing, Li Deming, Fan Jianli. Research on Applied Undergraduate Mixed Teaching under the Background of "Gold Class" -A Case Study of Tourism Management Major in Huangshan University $[\mathrm{J}]$. Journal of Guangxi Normal University of Science and Technology,20,35(04):121-123.

[11] Li Mei, Luo Huixiao. Analysis of Talent Training for the Matchmaking between Major and Post in Secondary Vocational Schools under the Background of "School-Enterprise Integration" -Taking Tourism Service and Management Major as an Example [J]. Guangxi Education,2020(30):50-51.

[12] ZHENG Haiming, WU Hong. Construction of "itinerary-type" classroom teaching mode based on mobile interactive teaching method in higher vocational tourism management specialty [J]. Journal of Qiqihar Teachers College,2020(04):130131.

[13] Jie Jie. Exploring the Teaching Mode of Tourism Management Major in Contemporary Higher Vocational Colleges -- Taking the Students of Tourism Management Major in Gansu Province as an Example [J]. Chinese Journal of Management Informatization,2020,23(14):217-218.

[14] Wu Jiangzhou, Wei Xin. Research on Social Practice Course for Tourism Management Major: A Case Study of Tourism Management Major in Central South University of Forestry and Technology [J]. Science and Education Guide (Upper Ten),2020(07):60-61.

[15] Hu Hao. Ma Yong, Deputy Director of the Teaching Steering Committee of College Tourism Management, Ministry of Education: Brand Building and Marketing Innovation of National Tourism Resort [N]. China Tourism News,2020-0701(003).

[16] Xu Ke. Exploration of Practical Teaching Reform in Higher Vocational Colleges -- Taking the Tourism Management Major of Kaifeng University as an Example $\quad[\mathrm{J}]$. Journal of Kaifeng University,2020,34(02):57-59. 